\title{
Medullary Thyroid Carcinoma Surveillance Study: A Case-Series Registry
}

\author{
Paula M. Hale, ${ }^{1}$ Ayad K. Ali, ${ }^{2}$ John B. Buse, ${ }^{3}$ Mary Kate McCullen, ${ }^{4}$ Douglas S. Ross, ${ }^{5}$ \\ Mary Elizabeth Sabol, ${ }^{6}$ R. Michael Tuttle, ${ }^{7}$ and Annette Stemhagen ${ }^{8}$
}

$\mathbf{T}$ he Medullary Thyroid Carcinoma (MTC) Surveillance Study [the MTC registry (1)] is a case-series registry established in 2010 as a Food and Drug Administration (FDA) postmarketing commitment for liraglutide, the first long-acting glucagon-like peptide-1 receptor agonist (GLP-1 RA) approved in the United States. Subsequently, other GLP1 RAs have been developed and brought to market, including exenatide (AstraZeneca, PLC), albiglutide (GlaxoSmithKline, PLC), dulaglutide (Eli Lilly and Company), and semaglutide (Novo Nordisk A/S), and are included in the MTC registry. Additional pharmaceutical companies (sponsors) who receive FDA approval for new GLP-1 RA products may also be asked to participate in this registry.

Studies in rodents, but not in monkeys, with clinically relevant doses of GLP-1 RAs, showed a dose-related and treatment-duration-dependent increase in the incidence of C-cell hyperplasia and C-cell tumors (adenomas and carcinomas) (2,3). The clinical relevance of rodent thyroid findings observed with GLP-1 RAs is unknown. Based on the preclinical data, and due to the low population-level incidence of MTC (estimated by the North American Association of Central Cancer Registries (NAACCR) to be 0.24 cases per 100,000 person-years in 2001-2009 before introduction of GLP-1 RA into the U.S. market) (North American Association of Central Cancer Registries, pers. comm.), the FDA required the sponsors with approved long-acting GLP-1 RAs collaborate in conducting an active surveillance study to evaluate this potential association in humans. Consequently, the MTC registry consortium was formed with the GLP-1 RA sponsors, the American Thyroid Association, and United BioSource Corporation (UBC, a contract research organization that conducts the study on behalf of the sponsors). A steering committee and registry data monitoring committee (RDMC) consisting of clinicians and scientists with expertise in cancer epidemiology, endocrinology (diabetes, thyroid, and obesity), and biostatistics provide oversight for the MTC registry.
The objectives of the MTC registry are to (a) systematically monitor the annual incidence of MTC in the United States to identify any possible increase related to the introduction of long-acting GLP-1 RAs into the U.S. market and (b) establish a registry of incident cases of MTC in adults in the United States to characterize their medical histories and possible risk factors, including history of treatment with long-acting GLP-1 RAs. The annual incidence of MTC will be documented for 15 years after each long-acting GLP-1 RA approval, or a period agreed upon with the FDA and each sponsor. Given the very low incidence of MTC in the general population, the expected rate of exposure to long-acting GLP-1 RAs, the anticipated long latency of the potential outcome, and limited data on underlying risk factors for MTC, an active surveillance program based on NAACCR data was deemed to be effective. These data obtained from NAACCR represent nationwide aggregate data on the incidence of MTC in the United States. The timeframe before the introduction of long-acting GLP-1 RAs into the U.S. marketplace (January 1, 2001 to December 31, 2009) forms the baseline data for MTC incidence.

Twenty-eight State Cancer Registries (SCRs; with an average of at least 10 reported cases of MTC per year) were invited to participate in the surveillance program. The participating SCRs represent $\sim 84 \%$ of the U.S. population and $85 \%$ of the annual incident MTC cases.

The incident MTC cases reported by a participating SCR are enrolled after appropriate consent. Additional information to what is provided directly from the SCR is collected by trained representatives from UBC through telephone interviews with patients. Using a standard interview questionnaire, this information includes presence of risk factors, comorbid conditions, history of diabetes, and history of exposure to long-acting GLP-1 RAs. If a patient reports treatment with a long-acting GLP-1 RA or a diagnosis of diabetes, the treating physician is requested to complete a physician

\footnotetext{
${ }^{1}$ Novo Nordisk Inc., Plainsboro, New Jersey, USA.

${ }^{2}$ Eli Lilly and Company, Indianapolis, Indiana, USA.

${ }^{3}$ University of North Carolina School of Medicine, Chapel Hill, North Carolina, USA.

${ }^{4}$ BioPharmaceuticals Medical, AstraZeneca, Wilmington, Delaware, USA.

${ }^{5}$ Massachusetts General Hospital, Boston, Massachusetts, USA.

${ }^{6}$ GlaxoSmithKline Research \& Development Limited, Collegeville, Pennsylvania, USA.

${ }^{7}$ Memorial Sloan Kettering Cancer Center, New York, New York, USA.

${ }^{8}$ United BioSource LLC, Blue Bell, Pennsylvania, USA.
}

(c) Paula M. Hale et al., 2020; Published by Mary Ann Liebert, Inc. This Open Access article is distributed under the terms of the Creative Commons Attribution Noncommercial License (http://creativecommons.org/licenses/by-nc/4.0/) which permits any noncommercial use, distribution, and reproduction in any medium, provided the original author(s) and the source are cited. 
verification form to confirm the information collected during the interview. Patients and physicians may receive a small honorarium compensating them for their participation in MTC registry, based on fair market value.

The institutional review board of each SCR approved the MTC registry protocol. All data collected during the conduct of the MTC registry are held in accordance with all applicable privacy laws. Each participating sponsor owns the deidentified data pertaining to MTC cases with exposure to their product. Data regarding another sponsor's product is deidentified to all other sponsors with respect to product exposure. Each of the MTC registry sponsors provides reports to the FDA at predetermined intervals. Serious adverse events and adverse events identified as spontaneous reports as a result of the data collected in the MTC registry are submitted to safety departments of the relevant sponsor(s) using standard reporting methods.

The RDMC is responsible for performing an ongoing and independent evaluation of accumulated data from the MTC registry, including product identification for specific exposure, while the sponsor representatives in the RDMC remain blinded to other sponsors' specific products. The steering committee is responsible for the scientific leadership and integrity of the MTC registry.

Limitations of this registry are the likelihood that (a) a relatively small number of individuals may be exposed to long-acting GLP-1 RAs and (b) variation in the background incidence and reporting of the MTC cases. Furthermore, there would have to be sufficient use of these agents in the population to distinguish an increase in the incidence due to exposure to these agents from typical background fluctuations in the rate of MTC. Varying state regulations on soliciting patient participation complicates the approach for this registry. The multisector partnership required a complicated communication plan and data security measures to ensure standardized data collection, analysis, and information sharing while ensuring privacy and confidentiality. While a single-sponsor-funded registry may provide simpler and elegant solution, a multisponsor registry such as the MTC registry offers the opportunity to detect any potential relationship between the use of GLP-1 RAs and a relatively rare form of cancer, such as MTC and reduced burden on patients and health care providers who only have to report patient data to one source. Increasing participation and support by health care providers and patients will further ensure a successful implementation of the MTC registry.

\section{Acknowledgments}

Writing assistance was provided by Radhika Adiga, MD, PhD, who is an employee of Novo Nordisk Inc. Andrea Lynn Davis provided data tables, editorial support, and project management support, including liaising between different steering committee member authors and sponsor authors, and is an employee of United BioSource LLC.

\section{Author Disclosure Statement}

P.M.H. is an employee and stock holder of Novo Nordisk Inc. A.K.A. is an employee and shareholder of Eli Lilly and Company. J.B.B. has contracted consulting fees paid to the University of North Carolina by Adocia, AstraZeneca, Dance
Biopharm, Dexcom, Elcelyx Therapeutics, Eli Lilly, Fractyl, GI Dynamics, Intarcia Therapeutics, Lexicon, MannKind, Metavention, NovaTarg, Novo Nordisk, Orexigen, PhaseBio, Sanofi, Senseonics, Shenzhen HighTide, Takeda, vTv Therapeutics, and Zafgen; he reports grant support from AstraZeneca, Eli Lilly, GI Dynamics, GlaxoSmithKline, Intarcia Therapeutics, Johnson \& Johnson, Lexicon, Medtronic, Novo Nordisk, Orexigen, Sanofi, Scion NeuroStim, Takeda, Theracos and vTv Therapeutics; he is a consultant to Cirius Therapeutics, Inc., CSL Behring, Neurimmune AG, and Whole Biome; he owns stocks/options in Mellitus Health, PhaseBio, and Stability Health; and he is supported by grants from the National Institutes of Health (UL1TR002489, U01DK098246, UC4DK108612, and U54DK118612), the Patient Centered Outcomes Research Institute, and the American Diabetes Association. M.K. M. is an employee and shareholder of AstraZeneca. D.S.R. has received consulting fees from the sponsors of the Medullary Thyroid Cancer Registry Consortium: Novo Nordisk, Astra Zeneca, GlaxoSmithKline, and Eli Lilly. M.E.S. is an employee and shareholder of GlaxoSmithKline. R.M.T. has received consulting fees from the sponsors of the Medullary Thyroid Cancer Registry Consortium: Novo Nordisk, Astra Zeneca, GlaxoSmithKline, and Eli Lilly. A.S. serves as a paid consultant to the MTC Consortium through UBC.

\section{Funding Information}

This registry is funded by Novo Nordisk Inc., AstraZeneca AB, GlaxoSmithKline Research \& Development Limited, and Eli Lilly and Company. This research was funded in part by the NIH/NCI Cancer Center Support Grant P30 CA008748 (Craig Thompson, PI; M.T.).

\section{References}

1. Medullary Thyroid Carcinoma (MTC) Registry Consortium. Available at: www.thyroid.org/professionals/partner-relations/ medullary-thyroid-carcinoma-registry-consortium (accessed May 11, 2020).

2. Bjerre Knudsen L, Madsen LW, Andersen S, Almholt K, de Boer AS, Drucker DJ, Gotfredsen C, Egerod FL, Hegelund AC, Jacobsen H, Jacobsen SD, Moses AC, Mølck AM, Nielsen HS, Nowak J, Solberg H, Thi TD, Zdravkovic M, Moerch U 2010 Glucagon-like peptide-1 receptor agonists activate rodent thyroid C-cells causing calcitonin release and C-cell proliferation. Endocrinology 151:1473-1486.

3. Madsen LW, Knauf JA, Gotfredsen C, Pilling A, Sjogren I, Andersen S, Andersen L, de Boer AS, Manova K, Barlas A, Vundavalli S, Nyborg NC, Knudsen LB, Moelck AM, Fagin JA 2012 GLP-1 receptor agonists and the thyroid: C-cell effects in mice are mediated via the GLP-1 receptor and not associated with RET activation. Endocrinology 153:15381547 .

Address correspondence to: Paula M. Hale, MD Novo Nordisk Inc. 800 Scudders Mill Road Plainsboro, NJ 08536 USA

E-mail: hale@novonordisk.com 